\title{
Identificación/producción del patrimonio inmaterial en Andalucía. Un análisis a través del caso de los Mosqueteros del Santísimo Sacramento de Béznar (Granada)
}

Identification/production of intangible heritage in Andaludia. An analysis through the case of the Musketeers of the Santísimo Sacramento of Béznar (Granada)

Juan de Dios López López

Taller ACSA. Granada (España)

jdlopez@taller-acsa.org

\section{José Francisco Ruiz Ruiz}

Consultor en Patrimonio Etnológico e Inmaterial. Granada (España)

flanaganruiz@yahoo.es

\section{RESUMEN}

El objetivo principal de este trabajo es mostrar que la identificación de patrimonio cultural y la producción de patrimonio cultural no constituyen dos procesos distintos, sino que ambas expresiones designan básicamente lo mismo: la asignación de valores patrimoniales a determinados elementos culturales. A partir del análisis de un caso concreto en el cuál hemos intervenido directamente, la fiesta de los Mosqueteros de Béznar en la provincia de Granada, señalamos cómo determinadas dimensiones y procesos sociales de la fiesta han sido transformados en 'valores culturales' en el proceso de identificación/producción patrimonial. Finalmente, abogamos por potenciar la capacidad del patrimonio como instrumento para la reflexividad cultural, lo que constituye para nosotros la principal tarea de la antropología en este ámbito.

\section{ABSTRACT}

The main objective of this paper is to show that the identification of cultural heritage and the production of cultural heritage are not separate processes, but rather both expressions serve basically the same aim: the allocation of heritage values to certain cultural elements. From the analysis of a case study in which we participated directly, the festival of Béznar Musketeers in the Andalusian province of Granada, we show how certain dimensions and social processes of the fiesta have been transformed into 'cultural values' in the process of identification / production of heritage. Finally, we argue that it is important to enhance heritage as a tool for cultural reflexivity, which, in our opinion, should be the main task of anthropology in this area.

"Los patrimonialistas no descubren, construyen herencia cultural" (José Antonio Fernández de Rota)

\section{Introducción}

En este trabajo pretendemos dar cuenta de cómo hemos intervenido directamente en un proceso de patrimonialización institucional, redactando el expediente de inscripción en el Catálogo General del Patrimonio Histórico de Andalucía (CGPHA) de la fiesta denominada los "Mosqueteros del Santísimo Sacramento" que se celebra en la localidad granadina de Béznar. 
Mostraremos de qué forma hemos identificado algunas dimensiones de la fiesta que, en el proceso de patrimonialización, han sido transformadas en "valores culturales". Para ello comenzaremos exponiendo el contexto institucional en el que se desarrolla este trabajo de documentación de la fiesta como parte fundamental de su proceso de patrimonialización institucional y continuaremos señalando las dimensiones sociales de este ritual festivo que hemos empleado para justificar su inscripción en el CGPHA: su raigambre histórica y su imbricación en las memorias colectivas, su centralidad en los procesos de identificación local y las formas de sociabilidad posibilitadas por el contexto festivo. El mero hecho de utilizar estas dimensiones en la justificación de la consideración patrimonial de este ritual es uno de los instrumentos principales por el que quedan transformados en "valores".

Como hemos expuesto en otro lugar (López 2011), uno de los mecanismos fundamentales utilizados en la transformación patrimonial de determinadas expresiones culturales es su presentación "desconflictualizada", de modo que puedan ser interpretadas en términos de "vinculación comunitaria" y no de expresión del conflicto. Sin embargo, como no podía ser de otra forma, el conflicto forma parte inherente de la mayor parte de las fiestas celebradas en Andalucía. Así, tras la descripción de las dimensiones utilizadas en la justificación patrimonial de las fiestas, analizamos dos aspectos de "Los Mosqueteros" que, si no obtuvieran una respuesta local adecuada y en gran medida consensuada, podrían dificultar la consideración patrimonial del ritual al discordar con ciertas expresiones declarativas de valor dominantes , como la igualdad de género o el desarrollo armónico de las relaciones entre las instituciones, la sociedad civil y la ciudadanía en general.

Finalmente, lejos de tratar de establecer unas conclusiones más o menos definitivas, abogamos por la potenciación de la capacidad reflexiva del patrimonio como la principal tarea del quehacer antropológico en este ámbito.

\section{Contexto institucional: la catalogación del patrimonio inmaterial en Andalucía}

El debate en torno al patrimonio inmaterial se ha intensificado notablemente en la última década. A ello ha contribuido de un modo muy especial la publicación en 2003, por parte de la UNESCO, de la Convención para la Salvaguarda del Patrimonio Inmaterial y el reconocimiento de diversas expresiones culturales como Patrimonio Inmaterial de la Humanidad, etiqueta otorgada por esta institución supranacional a candidaturas presentadas en concurrencia competitiva (Velasco 2012).

La mayor parte de las expresiones culturales, que tienen cabida bajo esta etiqueta, gozaban ya con anterioridad de cierto reconocimiento por parte de las legislaciones nacionales en Europa. Bajo diversas expresiones, siendo las más comunes las de Patrimonio Etnográfico o Etnológico, estas legislaciones nacionales incluían los aspectos de la cultura, no exclusivamente "materiales", que ahora se agrupan bajo el rubro de patrimonio inmaterial. En España, la primera referencia legislativa al patrimonio etnológico aparece en la Ley 16/1985, de 25 de Junio, de Patrimonio Histórico Español y, bajo diversas fórmulas (Pérez Galán 2011), se mantienen en el desarrollo legislativo al respecto desarrollado por las distintas comunidades autónomas. En el caso de Andalucía, la Ley 1/1991, de 3 de Julio, de Patrimonio Histórico de Andalucía, dedica el Título VII completo al "Patrimonio Etnográfico"; etiqueta que se cambia en el Título VI de la ley posterior (Ley 14/2007, de 26 de noviembre, del Patrimonio Histórico de Andalucía), por la de "Patrimonio Etnológico".

Como hemos apuntado antes, el encargo que asumimos fue realizar un estudio sobre la fiesta de "Los Mosqueteros del Santísimo Sacramento", de Béznar, con objeto de incluirla, por constituir una actividad con un interés etnológico destacado, en el CGPHA. En la Ley 14/2007 de Patrimonio Histórico de Andalucía, se establece el Catálogo General del Patrimonio Histórico Andaluz como un "instrumento para la salvaguarda de los bienes en él inscritos, la consulta y divulgación de los mismos". Existen tres tipologías de bienes que podrán ser incluidos en el catálogo: Bienes de Interés Cultural (BIC), Bienes de Catalogación General y los que se incluyen en Inventario General de Bienes Muebles del Patrimonio Histórico Español; siendo los primeros (BIC), los que gozarán del mayor grado de protección que prevé 
le ley. El fin del estudio en torno a la fiesta de Los Mosqueteros es incluir esta manifestación cultural como Bien de Catalogación General. El artículo 63 de dicha ley establece lo siguiente:

"La inscripción en el CGPHA de prácticas, saberes y otras expresiones culturales como actividades de interés etnológico les conferirá preferencia entre las de su misma naturaleza a efectos de su conocimiento, protección, difusión, así como para la concesión de subvenciones y ayudas públicas que se establezcan. Asimismo, serán especialmente protegidos aquellos conocimientos o actividades que estén en peligro de desaparición, auspiciando su estudio y difusión, como parte integrante de la identidad andaluza. A tal fin se promoverá su investigación y la recogida de los mismos en soportes materiales que garanticen su transmisión a las futuras generaciones" (Ley 14/2007, de Patrimonio Histórico de Andalucía).

Como puede observarse, la legislación establece el Patrimonio Histórico de Andalucía como el conjunto de elementos o rasgos diacríticos que definirían la identidad andaluza. Ya en la Exposición de motivos de la ley se considera al patrimonio como "la expresión relevante de la identidad del pueblo andaluz, testimonio de la trayectoria histórica de Andalucía y manifestación de la riqueza y diversidad cultural que nos caracteriza en el presente". La legislación confiere, por lo tanto, un sólido vínculo entre patrimonio e identidad. Nuestro punto de partida teórico difiere en el sentido de que la identidad no preexiste a su propia acción, a su puesta en escena. Dicho de otra forma, los procesos de construcción identitaria no son anteriores a los procesos de patrimonialización, sino que ambas expresiones designan un proceso único consistente en la elaboración de una narrativa del "nosotros" mediante la instrumentalización de expresiones culturales específicas. La diferencia, aunque parezca mínima, es notable. Durante la fase de redacción de la Documentación Técnica de los Expedientes de Inscripción de las fiestas en el CGPHA, hemos tenido en cuenta esta distinción, especialmente en el apartado que el Reglamento de Protección y Fomento del Patrimonio Histórico Andaluz (Decreto 19/1995) dedica a la justificación de la inclusión en el catálogo de cualquier actividad y que hace hincapié en la necesidad de esclarecer "los valores etnológicos (históricos, tradicionales e identitarios)" de la actividad en cuestión. En los siguientes epígrafes, dedicados a la descripción etnográfica y al análisis de la fiesta de los Mosqueteros, se recoge parte de la información a partir de la cual se ha elaborado la Documentación Técnica necesaria para la catalogación de la actividad.

Por último, es necesario aclarar que la iniciativa de inscribir estas fiestas en el CGPHA parte de la propia Delegación Provincial de la Consejería de Cultura de la Junta de Andalucía en Granada, que desde el año 2006 viene prestando una especial atención al Patrimonio Etnológico e Inmaterial de la provincia . Si bien las administraciones locales afectadas han iniciado algunos proyectos de patrimonialización de estas fiestas, sus esfuerzos se han inclinado más por resaltar su potencialidad como recurso de atracción turística.

\section{La celebración de la fiesta en la actualidad}

La localidad de Béznar pertenece al municipio de Lecrín, que está constituido por seis pueblos: Talará, Murchas, Acequias, Mondújar, Chite y Béznar. Este municipio se enclava en la comarca del Valle de Lecrín, en el centro de la provincia de Granada.

Béznar es una localidad eminentemente agrícola, destacando su producción de cítricos y frutales. Por otra parte, Béznar presenta un considerable descenso demográfico, debido, entre otros factores, a la emigración y al envejecimiento de su población. Entre 1986 y 2008 ha perdido alrededor del 24\% de su población, habiendo pasado de 458 habitantes en 1986 a 350 en 2008 .

En esta localidad se celebra cada primer fin de semana de septiembre un ritual festivo denominado "los Mosqueteros del Santísimo Sacramento", también conocido como "Ios Mosqueteros de Béznar" o "los Mosqueteros de San Antón". La fiesta se desarrolla durante las jornadas del sábado y el domingo, repitiéndose cada día la misma secuencia de actos. Además, el viernes anterior, los Mosqueteros desfilan por la tarde por las calles de la localidad para anunciar el comienzo de las fiestas. 
Sigue el modelo de las soldadescas, descritas por Brisset (2001) para el caso de las fiestas de Moros y Cristianos, con las que comparte algunas características, sobre todo con las celebradas en la Alpujarra y en la mayor parte de Andalucía. Sin embargo, no puede ser encuadrada dentro de éstas, puesto que carece de representación del enfrentamiento o las escaramuzas entre dos bandos.

El origen de las soldadescas son las milicias locales organizadas por los Reyes Católicos, encargadas de la protección del territorio circundante, que fueron incorporándose a la celebración de las festividades de sus respectivas localidades. Felipe II configuró la jerarquía de estas milicias estableciendo las siguientes figuras: capitán, alférez, sargento, cabo y soldados (Brisset 2001). En la actualidad, los Mosqueteros de Béznar se estructuran de un modo similar: teniente, sargento, cabo y mosqueteros.

\section{La producción de valores culturales en la transformación patrimonial de la fiesta}

A continuación presentamos algunos resultados del trabajo de campo, realizado en torno a la fiesta de los Mosqueteros, que han sido utilizados en la justificación de su carácter patrimonial, se trata de los procesos o dimensiones sociales que hemos propuesto como "valores culturales y patrimoniales" de la fiesta. Entre estas dimensiones se deben destacar las siguientes: 1) raigambre histórica de la celebración y sus implicaciones en la memoria colectiva, 2) centralidad del fenómeno dentro de los procesos de identificación local, y 3) las diversas formas de sociabilidad que propicia el contexto festivo.

\subsection{Raigambre histórica y memoria colectiva}

José Luis García (2000) distingue dos modalidades de ritual festivo: las celebraciones y las conmemoraciones. Estas últimas se definirían por estar firmemente ancladas a un hecho del pasado (o a una determinada versión de éste), por ajustarse a un guión estricto que marca todo el tiempo festivo y, sobre todo, por que la participación de la mayoría de los asistentes a la fiesta es pasiva, observándose una clara distinción entre protagonistas y espectadores. Por el contrario, en las celebraciones la frontera entre protagonistas y espectadores sería mucho más difusa y la participación en general más activa, el guión tendría mayor flexibilidad y el anclaje al "hecho pasado" sería menor. Pues bien, en la actualidad, los Mosqueteros del Santísimo se entienden mejor como una celebración del "estar juntos" y como un contexto para la reafirmación y reconstrucción de la(s) identidad(es) local(es), que como la conmemoración de un hecho histórico concreto. Aunque hubiese sido creada en su origen como una conmemoración dirigida a la "resemantización del territorio", tras la expulsión de la población morisca (González Alcantud 2002: 148-170). Como explica José Luis García, determinados acontecimientos pueden provocar que una conmemoración terminé convirtiéndose en una celebración y, al contrario, que una celebración se transforme con el tiempo en una conmemoración.

En efecto, el origen de la fiesta de los Mosqueteros del Santísimo Sacramento de Béznar es la conmemoración de la victoria de una milicia local al rescatar el sagrario y a una mujer joven, que habían sido secuestrados por un grupo de moriscos sublevados antes de iniciarse la guerra de las Alpujarras (1568-1571). Estos hechos, recogidos por algunos historiadores y eruditos locales (Sánchez 2004, Río 2006), han formado parte de la tradición oral de Béznar. Un hombre de 82 años que reside alternativamente entre Béznar y Granada capital nos relataba esta historia de un modo muy expresivo:

"Mataron a dos y se llevaron a una mujer, también, con ellos, y la hirieron, le cortaron un brazo, y con las mismas pues se fueron. Ya habían hecho cosas en el pueblo, estaban siempre haciendo cosas. Pero ya la gente se cansó y dijeron que iban a ir con lo que fuera en busca de ellos. Entonces les dijeron que no fueran, que no fueran porque ellos tenían sus alfanjes y sus cosas y los iban a matar a todos. Pero la gente, sobre todo los mozuelos, ya dijeron: 'vamos a por lo que sea'. Pero resulta que aquí, por aquellos entonces, venía a veranear mucha gente. Venía Don Juan de Austria que tenía un sitio ahí, donde paraba, que le llaman el Palacio.... Y por entonces 
había también ahí un señor, que era un alférez, de los tercios de Flandes, que estaba aquí. Y les dijo: 'no, no, no, quietos, vamos a ver'. Y por mano de él, fueron a Granada y consiguieron que Don Juan de Austria les diera unos mosquetes, les dio 25 mosquetes. Entonces, con eso ya sí. Claro, los sarracenos no conocían la pólvora. Claro, cuando llegaron y pegaron cuatro tiros por estos barrancos y retumbaba todo, dijeron los moros: 'vámonos de aquí...'. Llegaron y se encontraron a la muchacha en una cueva. La muchacha, por lo visto, en un descuido... porque los sarracenos hacían burla del Santísimo... entonces, la muchacha en un descuido cogió el Santísimo y se lo guardó en el pecho. En eso fue cuando llegaron los mosqueteros. Luego a la muchacha le dieron una paga para toda la vida... Entonces, los mosqueteros se vinieron para abajo, a gusto, con el Santísimo" (E2).

En algunas ocasiones, se ha recogido esta historia en el programa de fiestas de la localidad, lo que, sin duda, ha contribuido a fijar algunos elementos de la tradición oral. Transcribimos algunos fragmentos del relato que se publico bajo el título Historia de los mosquetes en el programa correspondiente al año 2005.

"La política intransigente de Felipe II hace crecer el descontento de la población morisca y el aumento de los grupos de monfíes. Esta situación provoca enfrentamientos entre los moriscos y los cristianos como el sucedido en Béznar en torno al año 1566. Sucedió que una fracción de la partida de Igrahín Agad de la Zubia de los monfíes del Nazcoz de Nigüelas atacó al Beneficiado y a su séquito cuando se dirigía a dar el Santísimo a un enfermo. Resultando muerto el Sacristán y un labrador, siendo cautiva la hija de éste, María Trinidad y robado el Santísimo que era conducido en el portaviático.

Conocido el suceso, el pueblo se reunió en la plaza y los hombres querían perseguir a los monfíes si no hubiesen sido impedidos por las autoridades. En esta confusión se presentó un alférez de los tercios de Flandes, D. Martín Alonso de Frías, el cual organizó una Hermandad cuya principal misión era rescatar al Santísimo, para ello acudieron al Marqués de Mondéjar D. Luis Hurtado de Mendoza que les concedió 25 mosquetes y arcabuces...

D. Juan de Austria conoció de todas estas hazañas por boca del alférez Martín Alonso de Frías. El Príncipe concedió a María Trinidad una pensión como premio a su heroísmo y alos mosqueteros el privilegio de escoltar el Santísimo, a la vez que los uniformaba. Todo esto sucedió en Béznar, según constaba en un manuscrito de 1571 que existía en el Archivo Parroquial de Béznar" (Programa de las Fiestas en Honor a San Antón de Béznar 2005).

El conocimiento de este relato histórico es sólo uno más de los instrumentos que los individuos pueden usar para vincularse al resto del grupo en el contexto de la fiesta (de hecho, entre nuestros informantes, protagonistas destacados en el ritual, se dan muchas confusiones acerca del origen, y no son pocos quienes lo sitúan en la conquista de Granada por los Reyes Católicos en 1492). En este sentido, mucho más importante que conocer el hecho en sí, se pueden enumerar otros elementos que vehiculan la identificación con el grupo: la adecuada ejecución de los ritos, la correcta colocación de los distintos componentes de la indumentaria y, sobre todo, la participación continuada, año tras año, en la fiesta.

Los Mosqueteros del Santísimo forman parte de la memoria colectiva de "los bezneros", pero esta memoria no está construida sólo por los hechos sancionados por los historiadores y los textos escritos, sino que se trata de una memoria basada en la experiencia y construida en un ámbito local y/o doméstico.

Cuando se interroga a los participantes acerca de las motivaciones que les llevan a actuar en la fiesta o se les pregunta qué es lo que sienten cuando se visten de Mosqueteros y desfilan por las calles de Béznar, la respuesta más habitual tiene que ver con el recuerdo de la participación de sus familiares y con el deseo de formar parte de una celebración única que identifica al pueblo de Béznar en el contexto de la provincia y de la comunidad autónoma. A esta pregunta nos respondieron varios participantes en la fiesta, reproducimos a continuación sus palabras. El primer párrafo corresponde a un joven de 28 años, el 
siguiente a un hombre de 40 años y el último a un muchacho de 16, los tres residen en el municipio.

"Lo que siento... pues es un cúmulo de sensaciones que no se pueden explicar. Mi padre salió de abanderado, mi hermano también, yo he salido de abanderado, he salido también de mosquetero, y es que lo lleva uno en la sangre, le gusta, paga por hacerlo... y ya te digo, no se puede explicar, es una sensación muy grande" (E6).

"Yo empecé a salir de mosquetero porque te hace ilusión. Lo ves desde chiquitillo, lo mamas... y es una cosa, que es un orgullo salir en tus fiestas... y es una manera de rendir un homenaje a tu pueblo" (E4).

"Es una cosa única de este pueblo, que se conoce ya por muchas zonas de todo el valle, en Granada también hemos estado, en Sierra Nevada... y todo el que lo ha visto se ha quedado impresionado" (E8).

El "valor histórico" de la fiesta no procede de su capacidad para transmitir una serie de conocimientos académicos sobre el siglo XVI, aunque también puede actuar de esa manera. Su "valor histórico", a nuestro juicio, radica en el uso que le han dado sus protagonistas para crear una sensación de continuidad con el pasado, para dotar de la cualidad de antepasados a quienes, de una forma u otra, celebraron la fiesta con anterioridad. Se produce así un "enlace de tiempos" (Fernandez 2004) que vincula al presente con el pasado para proyectar, al "nosotros" escenificado en la fiesta, hacia el futuro.

\subsection{Centralidad de la fiesta en los procesos de identificación local}

La mayoría de estudios sobre el ritual, y concretamente sobre los de carácter festivo, subrayan la importancia de éstos en la construcción social de identificaciones colectivas. Esto ha producido un cierto automatismo en el ámbito de las ciencias sociales y se ha asumido la relación entre ritual e identidades sin aportar las explicaciones necesarias a este respecto.

"Atribuir al ritual la capacidad de construir identidades sociales... puede ser una obviedad si no se justifica la relevancia y especificidad de esa construcción. Identidades sociales las producen los encuentros esporádicos entre personas, la coincidencia de la gente en las instituciones, la participación en un viaje organizado, las desgracias colectivas... Casi todos los acontecimientos de la vida social son susceptibles de desarrollar una dimensión identitaria" (García 1999: 502).

De este modo, es importante tener presente que la mera existencia de la fiesta no genera identidad por sí sola, sino que constituye un elemento cultural que, al ser revestido de significados y valores patrimoniales, se convierte en un instrumento poderoso para la reafirmación, reformulación y escenificación de "lo beznero" frente a "lo no beznero".

La centralidad de la celebración de los Mosqueteros del Santísimo en los procesos de identificación local, que adquiere tintes étnicos por el uso de un lenguaje biologizante ("lo lleva uno en la sangre"), puede observarse a partir de un enfoque emic y de la utilización icónica de la imagen del Mosquetero asociada a la localidad. Esto no quiere decir que los protagonistas de la fiesta no participen de otra serie de procesos de identificación colectiva, pero en este contexto festivo es la construcción y reafirmación de la identidad local lo que adquiere mayor relevancia, lo que se pone en escena.

Por otra parte, los Mosqueteros del Santísimo Sacramento han posibilitado a la sociedad de Béznar verse reconocida en el exterior, a pesar de su reducido número de habitantes y su paulatina despoblación. O de otra forma, le ha permitido auto-reconocerse en el reconocimiento exógeno. Por eso son tan importantes, dentro del imaginario de "los bezneros", las salidas que han hecho los Mosqueteros fuera de la localidad. Aún hoy, y aunque muchos no tienen un recuerdo empírico, las gentes de Béznar relatan al visitante el papel que los Mosqueteros desempeñaron en el Congreso Eucarístico que se celebró en Granada en 1957; y por el mismo motivo, muchos explican su malestar por la posición 
"folklórica" que les adjudicaron en la procesión del Corpus de Granada en 2008. Antonio, un hombre que comenzó a desfilar como mosquetero a principios de los 50, sí que estuvo en ambas ocasiones y nos lo contó así:

"Ese año volvieron a ir otra vez a escoltar el Santísimo [a Granada, durante las fiestas del Corpus de 2008]. Fueron, pero no fueron escoltando al Santísimo. Fueron delante, como si fueran otra cosa distinta. Pero es que cuando nosotros fuimos [Congreso Eucarístico de 1957], fuimos escoltando al Santísimo, delante de la Custodia. Pero el año pasado iban como folklore, al lado de la Tarasca, y los Mosqueteros no es eso, los Mosqueteros no es folklore, los Mosqueteros es lo que es y deben de ir por donde tienen que ir, con la Custodia" (E2).

Por último, a pesar del invocado origen histórico de la fiesta, situado en la victoria local sobre un grupo de moriscos, los procesos de construcción identitaria que se activan mediante el ritual, se debe insistir en ello, tienen un marcado carácter local. Dicho de otra forma, las identidades escenificadas durante el tiempo festivo se construyen (en oposición dialéctica y no en confrontación) frente al "otro" no local, frente al "no beznero"; y no frente a un fantasmagórico "otro" caracterizado como "moro", "morisco", "sarraceno" o "monfí". Para conservar las huellas del pasado, antes hay que borrar sus cicatrices. Como escribe Francisco Checa, refiriéndose a las fiestas de moros y cristianos (muy emparentadas con la festividad de los Mosqueteros): "posibilita una reproducción, simbólica, de identidades. De tipo local (ser del pueblo), de clase social (saneados o pobres), familiar (de prestigio) y grupal (de género y edad). En la actualidad en ningún pueblo se reproduce la identidad ideológico-cultural de representar a los vencedores" (Checa 2000: 24).

Antes de su declaración institucional, la instrumentalización de las fiestas como expresión de los procesos de identificación local supone el primer paso hacia su activación patrimonial. El tratamiento patrimonial que reciben las fiestas por parte de la población local es una condición básica para su reconocimiento institucional y la única garantía para la "salvaguarda" y continuidad del ritual.

\subsection{Sociabilidad y formas de participación}

El marco festivo propicia diversas formas de participación y contextos de sociabilidad con distintos niveles de formalidad, a pesar de la aparente rigidez del guión que articula el conjunto de actos que tienen lugar durante este ritual festivo, y de que la tropa de mosqueteros está encarnada por un número relativamente reducido de personas (una veintena de adultos y una decena de niños aproximadamente).

Si la actuación de los mosqueteros puede ser considerada el elemento central de la fiesta, hay que tener presente que "salir de mosquetero" no es la única forma de participar. Como recuerda Rodríguez Becerra, a diferencia del espectáculo, la fiesta "supone participación, aunque ésta sea a niveles tan elementales como pasear o consumir" (Rodríguez 1982: 12). Se pone así de relieve, frente a sus componentes conmemorativos, el carácter de la fiesta como celebración. En este sentido, la capacidad de una persona para sancionar el "buen hacer" de los mosqueteros, aunque ocupe una posición espacial que a priori induzca a pensar que se trata de un mero espectador, puede considerarse una forma de participación intensa, que requiere de un conjunto de conocimientos previos, adquiridos a través de la experiencia festiva .

Determinados actos de la secuencia festiva pueden hacer aún más difusa la frontera entre protagonistas y espectadores, por ejemplo, durante la procesión, donde el conjunto de los bezneros se une al desfile ocupando distintas posiciones. Por supuesto, en los actos menos protocolarios, como la comida popular y los juegos infantiles, es prácticamente imposible establecer ni siquiera de forma difusa esta distinción.

El contexto festivo, por otra parte, propicia ocasiones para el desarrollo de formas de sociabilidad que a lo largo del año es complicado que se establezcan en Béznar. Por un lado, el regreso de los emigrantes con ocasión de las fiestas fomenta el reencuentro de grupos de amistad, dispersos durante la mayor parte del año, en el espacio público. Aunque no es la única ocasión en la que "los bezneros", que residen 
habitualmente en otros puntos geográficos, vuelven a la localidad, sí que es la que mejor posibilita que estos encuentros se produzcan en el espacio público, puesto que la mayor parte del desarrollo de la celebración tiene lugar en las calles y plazas del casco urbano.

Merece la pena detenerse en algunos aspectos de la fiesta que la emigración ha contribuido a transformar. Por un lado, parece claro que, como afirma Salvador Rodríguez Becerra (1982), la emigración andaluza ha favorecido la revitalización de este tipo de rituales festivos y su patrimonialización, al convertir "el abandono de las tradiciones en pérdida doliente" (Velasco 2000: 121). Pero está revitalización, provocada por la emigración, forzosamente ha implicado cambios en el protocolo de la celebración. Los Mosqueteros del Santísimo Sacramento se insertan en las Fiestas Patronales en Honor a San Antón de Béznar y, hasta mediados del siglo XX, se celebraban en el día dedicado a esta advocación: el 17 de enero. En la actualidad, las fiestas patronales se celebran el primer fin de semana de septiembre, aunque se mantiene como festivo el 17 de enero y algunas personas, sin usar el traje de mosqueteros ni desfilar, salen a la puerta de su casa o a la plaza para disparar sus mosquetes.

Quizás en el ámbito español haya sido Honorio Velasco (1982 y 2000) quien más se haya detenido a estudiar la dimensión temporal de de las fiestas y sus implicaciones en el calendario. Una de sus conclusiones es que, a pesar de los conflictos que se generaron cuando el traslado de fecha fue "una propuesta tímidamente formulada por los emigrantes" (2000: 111), la opción de celebrar las fiesta en temporada estival terminó generalizándose en la mayor parte de los pueblos de la península. Uno de los argumentos utilizados a favor del cambio ha sido, según constata Velasco, y los Mosqueteros del Santísimo no son una excepción, la menor probabilidad de que se produzcan fenómenos meteorológicos adversos en verano.

"Se aguó la fiesta" y algunas otras expresiones más son indicadores de la peculiar caracterización de la fiesta como un tiempo claro, soleado. El mal tiempo 'desluce' la fiesta. La fiesta mayor se traduce en términos de "brillantez" y "esplendor". En la fiesta, el tiempo meteorológico metaforiza (¿o tal vez metonimiza?) el tiempo social" (Velasco 1982: 21).

Un "beznero", que reside en Granada gran parte del año, nos decía respecto a los Mosqueteros del Santísimo:

"Como el 17 de enero casi siempre llueve y hace mal tiempo... y esta fiesta con el colorido que tiene, la ropa que hay... pues la dejaron para septiembre, para el primer domingo de septiembre..." (E2).

Las fases previas a la celebración propiamente dicha también posibilitan el encuentro de grupos informales asociados a las diferencias de género. Las mujeres, que tradicionalmente se han encargado de la confección del traje de los mosqueteros, se suelen reunir en algunos domicilios para prestarse ayuda mutua, enseñar a las más jóvenes y pasar tiempo juntas. Los varones que saldrán de mosqueteros también se reúnen los días previos a la fiesta para ensayar los pasos, los cruces, la escolta, etc., e introducir a los nuevos mosqueteros en el ritual.

La suspensión temporal de la rutina cotidiana y la generación de un espacio para la convivencia y el encuentro lúdico constituyen, desde el punto de vista patrimonial, "valores" de la fiesta. Sin encuentro, sin sociabilidad, no es posible la fiesta que puede ser definida como un modo de interacción social destinado a celebrar la interacción misma.

\section{Respuestas locales al conflicto}

\subsection{Relaciones con la institución eclesiástica}

Existe una evidente vinculación entre la fiesta de los Mosqueteros del Santísimo Sacramento y determinados significantes del catolicismo, especialmente con el sagrario, la custodia y la imagen de San 
Antón. Esta conexión, a lo que hay que sumar la actuación de los mosqueteros durante la celebración de la misa en las fiestas, implica que necesariamente se establezcan relaciones con el clero y la propia institución eclesiástica. En Béznar, estas relaciones con la jerarquía católica, representada en la figura del párroco, han sido en algunas ocasiones conflictivas.

"Hay algunos curas que se han puesto un poco tontos, algunos no han querido que entrasen los mosqueteros. Había un cura que no entendía aquello, pero un cura que va a un pueblo, se tiene que ir con el pueblo. Y si el pueblo tiene una costumbre, respétala y te querrán porque, como te pongas en contra, el pueblo puede más que tú. Entonces, este cura dijo que no entraran los mosqueteros y se quedaron todos en la puerta, pero estando allí hablando, dijeron: ‘ ¿por qué no vamos a entrar?'. Pero en vez de entrar dos fueron todos, todos enteros, allí, encima del altar. Y el cura ya no sabía que hacer... Y cuando subieron los mosqueteros arriba, se formó un palmoterío en la iglesia que el cura tuvo que agachar la cabeza y tragarse aquello. Al año siguiente, estaba el mismo cura y se hizo normal, porque no puedes tú hacer lo que quieras" (E2).

Aunque sucesos de este tipo no son muy habituales, sí que se repiten en otras localidades donde determinados personajes de las fiestas tienen un papel destacado durante la eucaristía . Estos conflictos adquieren bastante importancia, desde un punto de vista analítico e interpretativo, porque en su resolución puede observarse la importancia de la vinculación a las imágenes religiosas en los procesos de identificación local y como éstas son, ante todo, una propiedad colectiva, "comunal". En palabras de Antonio Ariño:

"No abundan este tipo de incidentes, porque, aunque a disgusto, en general el clero es mucho más transigente y acomodaticio. Pero lo que todas estas formas de relación, conflictivas o no, ponen de relieve es la vinculación de la imagen con la expresión simbólica de la identidad colectiva, lo que supone considerarla propiedad comunal antes que eclesiástica" (Ariño 2003: 480).

"El cura se tiene que ir con el pueblo", "el pueblo puede más que tú", "no puedes hacer lo que tú quieras", etc., son expresiones que denotan, por un lado, la relevancia de la fiesta en la construcción de la identidad local y, por otra parte, como la sociedad de Béznar, "el pueblo", representado en los Mosqueteros, es durante la celebración la más alta autoridad de la localidad (Brisset 1997), por encima de las jerarquías civiles y religiosas.

Por otra parte, esta vinculación con la institución eclesiástica ha facilitado que, a través de los Mosqueteros del Santísimo, la sociedad de Béznar se haya visto reconocida más allá de los límites de su localidad. Desde el punto de vista local, el hito más importante en este sentido fue, como ya se ha señalado, la participación de los Mosqueteros en el IV Congreso Eucarístico Nacional, celebrado en Granada entre los días 15 y 19 de mayo de 1957.

En Béznar, los Mosqueteros del Santísimo representan el "producto local" por excelencia ("es lo único que hay", nos dicen nuestros informantes). En los últimos tiempos, las gentes de Béznar están comenzando a generar un discurso en torno a la patrimonialización de los Mosqueteros, en tanto que recurso cultural susceptible de explotación turística. Este proceso de activación patrimonial se inició ya en el Congreso Eucarístico de 1957, cuando la imagen de los mosqueteros que difundieron los medios de comunicación de ámbito provincial y nacional (cfr. Río 2006: 177-187), permitió que la sociedad de Béznar observara la posibilidad de que la escenificación del "nosotros", que se produce en la fiesta, contribuyese de forma adecuada a situar su localidad en el mapa turístico de la provincia. La creación de un museo de los Mosqueteros en el Edificio de Usos Múltiples de Béznar que, en la actualidad, se está promoviendo desde el Ayuntamiento de Lecrín es una muestra de este proceso, en el que se combina el discurso patrimonializador con la utilización turística del recurso.

\subsection{Roles de género y ritos de paso en la fiesta}


La utilización del mosquete ha estado tradicionalmente reservada a los varones adultos. Utilizar por primera vez un mosquete supone, para los muchachos, incorporarse a este mundo de adultos, aunque sea ocasionalmente, durante el desarrollo de la fiesta. En este sentido, la fiesta puede ser considerada un rito de paso (Van Gennep 2008), donde la puerta de entrada se materializa en el uso del mosquete. Si bien los niños y niñas son integrados en el desarrollo de la fiesta a edades muy tempranas, no es hasta la edad de 16 o 17 años aproximadamente cuando comienzan a utilizar los mosquetes.

En la fiesta pueden observarse niños y niñas en torno a los tres años que llevan la misma indumentaria que los adultos que se incorporan al desfile y marcan el paso junto a sus mayores, sobre todo por la tarde y durante la procesión. Hasta los 13 o 14 años llevan armas de juguete con las que simulan el porte del mosquete, y algunas veces el disparo mediante la utilización de petardos. A partir de esa edad, algunos muchachos reciben de sus familias trabucos y armas más pequeñas que los mosquetes, con las que ya pueden utilizar pólvora, pero que no son cargadas. Sobre los 16 o 17 años, los chicos que manifiestan su interés en utilizar el mosquete comienzan a hacerlo, siempre que la familia esté de acuerdo y pueda permitirse el costo de encargar una réplica a una fábrica de armamento. Entonces, el muchacho se integrará totalmente en el grupo de mosqueteros y recibirá el mismo tratamiento y ritual, es decir, se disparará por la mañana en su casa para efectuar la recogida y realizará el desfile en su totalidad, no sólo durante los actos de la tarde.

La integración de niños y niñas en los actos de los mosqueteros no se ha producido hasta el último tercio del siglo XX. Hasta entonces, era una actividad exclusiva de los varones adultos, que a menudo habían pasado ya por el servicio militar.

Si la condición de mosquetero ha estado habitualmente reservada a los varones, desde las últimas décadas es cada vez más frecuente que se incorporen niñas al desfile durante los actos de la tarde. En opinión de algunos de nuestros informantes, estas niñas probablemente se incorporarán al grupo de los mosqueteros adultos. Hasta ahora, sólo en una ocasión una mujer se ha incorporado al desfile de los Mosqueteros adultos. Además, algún año ha habido tímidas propuestas para que fuesen mujeres quienes asumiesen los papeles de sargento y teniente.

"Respecto a la mujer mosquetera... ha habido sólo una muchacha que salió hace unos años, pero que ellas no se lanzan mucho. Hubo una intentona de salir de teniente y de sargento, pero al final no, a la gente no le gustó mucho la idea y no llegó a buen puerto. Con el tiempo saldrán, llegarán también, como a todos lados que están llegando" (E4).

Esta controversia, generada ante la incorporación de las mujeres al grupo de los mosqueteros, no ha adquirido el grado y la trascendencia que ha tomado en algunas otras fiestas, por ejemplo en algunos Alardes celebrados en el País Vasco (cfr. Bullen 2003), y las mujeres se están introduciendo paulatinamente en todos los niveles de participación de las fiestas y adquiriendo cada vez mayor protagonismo, siendo muy habitual que haya mujeres ocupando mayordomías y puestos destacados en la Comisión.

Por otro lado, la confección del traje de los mosqueteros, una actividad que siempre han realizado las mujeres, puede interpretarse también como un rito de paso. En el contexto local, los conocimientos y técnicas necesarios para la elaboración del traje de mosquetero han formado parte del conjunto de aprendizajes que las muchachas adquirían para iniciarse en la vida adulta de las mujeres. Durante el periodo de noviazgo, las mujeres comenzaban a ofrecer a sus novios mantones y otras prendas para que las llevasen durante las fiestas. Además, podían comenzar a colaborar en la confección del traje que llevaría el novio. Una vecina de Béznar, de 78 años de edad, nos relataba como aprendió a confeccionar el traje colaborando con su futura suegra.

"Mi suegra se puso mala y me dijo que si yo quería hacerle el traje a mi marido, que entonces era mi novio... y estuve aquel día y le ayudé en lo que ella me mandó. Fue el primero... Yo se lo hacía cada dos años, pues desde que yo empecé antes de casarme, usted ajuste el tiempo, hasta hace 24 años que se murió cada dos años le he hecho el traje... cuando murió mi marido 
Las desigualdades de género reflejadas en los diferentes roles festivos y los conflictos ocasionales con determinadas instituciones, como la Iglesia Católica, podrían invalidar el carácter patrimonial de las fiestas si no obtuvieran una resolución local y rompiesen el consenso en torno a sus "valores patrimoniales". En el caso que nos ocupa, el consenso en torno sus valores es sólido entre quienes participan en la fiesta, quienes toman parte en su organización y el conjunto de la población local. Si la valoración de una expresión cultural no obtiene unos niveles mínimos de consenso social y mediático, su declaración patrimonial por parte de las instituciones públicas aparecerá como una afrenta a otros grupos que nieguen los valores culturales aducidos y habrán de enfrentarse a un conflicto permanente. Mientras en torno a una fiesta, o cualquier otra expresión cultural, exista un conflicto acusado sobre los "valores" que condensa, será difícil crear un discurso patrimonialista aceptado y compartido por el propio grupo que la celebra.

\section{La identificación/producción de patrimonio como proceso reflexivo}

Los procesos de identificación local, las específicas formas de sociabilidad que se dan en el contexto festivo y su importancia en la construcción de las memorias colectivas constituyen procesos sociales que son transformados en valores culturales en el transcurso del proceso de identificación/producción patrimonial. Estas dimensiones, analizadas desde el punto de de vista de la identificación patrimonial, posibilitan la inclusión de fiesta de los Mosqueteros del Santísimo Sacramento en el ámbito del patrimonio cultural y su reconocimiento institucional efectivo mediante su inscripción en el CGPHA.

Identificar el patrimonio equivale a producir patrimonio. Identificar/producir patrimonio es un proceso mediante el cual se le añade un significado patrimonial a prácticas culturales, que son instrumentalizadas como señas de identidad. Los elementos patrimoniales, tal como advierte José Antonio Fernández de Rota en la cita que encabeza este texto, no están en algún lugar escondido a la espera de ser descubiertos; por el contrario, el patrimonio cultural (ya se clasifique como material o inmaterial) forma parte del modo de vida cotidiano de determinados grupos o colectivos y necesita pasar por el tamiz de los "sistemas expertos" (Velasco y otros 2006) para transformarse en "herencia cultural", digna de ser conservada o salvaguardada, o lo que es lo mismo, apta para insertarse en procesos de gestión. El reconocimiento de determinadas prácticas culturales como patrimonio posibilita a los agentes patrimonializadores insertar dichas prácticas en procesos de gestión institucional de la cultura y la diversidad , convirtiéndose así en importantes "instrumentos de gobernabilidad" (Lacarrieu y Álvarez 2002).

El reconocimiento institucional del carácter patrimonial de las fiestas presenta riesgos y oportunidades. A nuestro juicio, los principales riesgos de la patrimonialización institucional de las fiestas es que se burocratice su organización y gestión, de forma que esta sea asumida finalmente por "expertos en patrimonio" y no desde el ámbito local y, en consecuencia, se fosilicen sus formas, se dificulten los cambios y pierdan interés para la población que hasta ese momento le había dado soporte. Para sortear estos riesgos, los procesos de patrimonialización institucional deben acompañar a procesos de patrimonialización iniciados desde la sociedad local. Es decir, no puede haber patrimonio si éste no es reconocido a priori por sus propios protagonistas, si no se ha instrumentalizado ya como seña de identidad. En este sentido, el respeto por las formas locales de organización y gestión de las fiestas debe ser una prioridad en los procesos de patrimonialización.

Por otra parte, el reconocimiento institucional de la fiesta como patrimonio posibilita que sus legítimos propietarios, la sociedad local que le da vida, cuenten con instrumentos legales y administrativos que impidan la apropiación de las formas expresivas del ritual por parte de agencias o individuos cuyos intereses sean contradictorios con los de la propia comunidad, que en definitiva es la que ha creado la fiesta y la re-crea cíclicamente (cfr. Agudo 2003). Esta protección de la propiedad comunal del patrimonio cultural permite que la fiesta se inserte en circuitos de existencia más allá de la sociedad local 
-"mercados incluidos", como señala Emanuele Amodio (2006)- y se aleje del peligro de la mera mercantilización al mismo tiempo que del ensimismamiento identitario.

La fiesta de los Mosqueteros del Santísimo Sacramento, o cualquier otra fiesta inmersa en procesos de identificación/producción patrimonial, no necesita del reconocimiento institucional ni de informes etnográficos para continuar siendo lo que siempre ha sido: un contexto espacio-temporal para el encuentro, la sociabilidad y la construcción colectiva de la "comunidad imaginada".

Sin embargo, al indagar en las distintas "gramáticas de identidad/alteridad" (Baumann y Gingrich 2004) que intervienen en la fiesta y en su mismo proceso de patrimonialización, la antropología puede contribuir a potenciar la capacidad dialógica y reflexiva del patrimonio. La identificación/producción de la fiesta como patrimonio nos obliga a pensar en cuál es su posición en la cultura y en el proceso de construcción de las diferencias. Y esta reflexión hemos de hacerla necesariamente de forma conjunta entre administraciones públicas, científicos sociales y, por supuesto, los depositarios últimos del elemento patrimonializable: los participantes en la fiesta. La importancia de tal contribución nos obliga, como antropólogos, a seguir interviniendo y reflexionando en el ámbito del patrimonio cultural.

\section{Bibliografía}

Agudo, Juan

2003 "Patrimonio y derechos colectivos" en Elodia Hernández y Victoria Quintero (coords.), Antropología y patrimonio: investigación, documentación e intervención. Granada, Comares: 12-29.

Amodio, Emanuele

2006 "Bienes inmateriales y procesos culturales: definiciones y contradicciones", VII Encuentro para la Promoción y Difusión del Patrimonio Inmaterial de Países Iberoamericanos. Gestión del Patrimonio Inmaterial y la Diversidad Cultural. Bogotá, Marcela Giraldo: 61-70.

Ariño, Antonio

2003 "Las relaciones entre las asociaciones fiesteras y la institución eclesiástica. Una aproximación a la lógica de la religión popular", en C. Álvarez, M. J. Buxó y S. Rodriguez, La religiosidad popular III. Hermandades, romerías y santuarios. Barcelona, Anthropos: 471-484.

Baumann, Gerd (y Andre Gingrich) (eds.)

2004 Grammars of Identity/Alterity. A Structural Approach. New York, Berghahn.

Brisset, Demetrio

2001 "Fiestas hispanas de moros y cristianos. Historia y Significados", Gazeta de Antropología, n 17, art. 3. http://www.gazeta-antropologia.es/?p=3232

Bullen, Margaret

2003 “Transformaciones socio-culturales y la recreación de una fiesta”, Zainak, n 24: 937-953.

Checa, Francisco

2000 "La fiesta de moros y cristianos en Andalucía: una mirada desde la antropología", Antropológicas, $\mathrm{n}^{\circ} 4: 9-44$.

Díaz de Rada, Ángel

2007 "Valer y valor. Una exhumación de la teoría del valor para reflexionar sobre la desigualdad y la diferencia en relación con la escuela", Revista de Antropología Social, n 16: 117-158.

Dietz, Gunther (y Ángeles Piñar) 
2000 La cerámica granadina entre industrialización, folklorización y reapropiación local: Consumo cultural, habitus diferencial e identidad en una ciudad andaluza. Hannover, Verlag für Ethnologie.

Fernandez, James W.

2004 "El celtismo astur-gallego: una tradición nueva y vieja", en Carmen Ortiz (coord.), La ciudad es para ti: Nuevas y viejas tradiciones en ámbitos urbanos. Madrid, Anthropos: 37-54.

Fernández de Rota, José Antonio

2005 Nacionalismo, cultura y tradición. Barcelona, Anthropos.

García, José Luis

1999 "La religión como sistema público: conocimientos, creencias y prácticas", en Salvador Rodríguez (coord.), Religión y cultura, vol. 1. Sevilla, Consejería de Cultura y Fundación Machado: 501-512.

2000 "Los rituales: estructuras y escenificaciones", en Javier García Castaño (ed.), Fiesta, tradición y cambio. Granada, Proyecto Sur: 129-152.

González Alcantud, José Antonio

2002 Lo moro. Las lógicas de la derrota y la formación del estereotipo islámico. Barcelona, Anthropos.

Lacarrieu, Mónica (y Marcelo Álvarez)

2002 "Introducción: La plaza y la caverna. Dilemas contemporáneos de la gestión cultural”, en Mónica Lacarrieu y Marcelo Álvarez (comps.), La (indi)gestión cultural. Una cartografía de los procesos culturales contemporáneos. Buenos Aíres, Ciccus \& La Crujía: 5-18.

Ley 14/2007 de 26 de noviembre de Patrimonio Histórico de Andalucía.

http://www.juntadeandalucia.es/boja/boletines/2007/248/d/1.html

\section{López, Juan de Dios}

2011 "Tradición, conflicto y valores en la fiesta. Un enfoque intercultural del patrimonio inmaterial", en Javier García Castaño y Nina Kressova (coords.), Actas del I Congreso Internacional de las Migraciones en Andalucía. Granada: Instituto de Migraciones: 1893-1901.

http://migraciones.ugr.es/congreso2011/libroacta/Mesa17/012_Lopez.pdf

Pérez Galán, Beatriz

2011 "Los usos de la cultura en el discurso legislativo sobre patrimonio cultural en España. Una lectura antropológica de las figuras leales de protección", Revista de Antropología Experimental , n 11: 11-30. http://www.ujaen.es/huesped/rae/articulos2011/02perez11.pdf

Río, Ana María

2006 Los Mosqueteros del Santísimo Sacramento, Granada, Velocitynet.

Sánchez Ramos, Valeriano

2004 "El culto eucarístico en la Berja barroca. Una propuesta de análisis para el ámbito granadino", en V. Sánchez Ramos y J. Ruiz Fernández (coord.), La Religiosidad popular y Almería: actas de las III Jornadas. Almería, Instituto de Estudios Almerienses: 357-392.

Rodríguez Becerra, Salvador (dir.)

1982 Guía de fiestas populares de Andalucía. Sevilla, Consejería de Cultura de la Junta de Andalucía.

UNESCO

2003 Convención para la Salvaguardia del Patrimonio Cultural Inmaterial.

http://unesdoc.unesco.org/images/0013/001325/132540s.pdf

Van Gennep, Arnold

1965 Los ritos de paso. Madrid, Alianza, 2008. 
Velasco, Honorio (ed.)

1982 Tiempos de fiesta. Ensayos antropológicos sobre las fiestas en España. Madrid, Tres-catorcediecisiete.

Velasco, Honorio

2000 "Tiempos modernos para fiestas tradicionales", en Javier García Castaño (ed.), Fiesta, tradición y cambio. Granada, Proyecto Sur: 97-128.

Velasco, Honorio

2012 "De patrimonios culturales y sus categorías", Gazeta de Antropología, nº 28 (3), art. 13.

http://www.gazeta-antropologia.es/?p=4066

Velasco, Honorio (y otros)

2006 La sonrisa de la institución. Confianza y riesgo en sistemas expertos. Madrid, Editorial Universitaria Ramón Areces. 